\title{
"A universidade ainda está aberta?" : o que diz a comunidade do entorno sobre a Universidade Federal do Pampa
}

Isadora Cabreira da Silva Graduanda em Pedagogia pela Universidade Federal do Pampa (Unipampa)

\section{Resumo}

O presente trabalho trata-se de uma pesquisa de campo produzida no município de Jaguarão/RS sobre as visões da comunidade em relação à Universidade Federal do Pampa - Campus Jaguarão. Assim, desenvolveu-se um estudo de caso, durante o ano de 20I8, nos bairros periféricos que estão no entorno da universidade. Através de um questionário foram alcançados sessenta e seis sujeitos de pesquisa. Com estes, após a coleta, foi produzida uma análise de dados que nos sugere o tipo de relação que essa comunidade possui com a universidade. Os dados indicam que, apesar do impacto positivo da instituição, sendo considerada mais um elemento para o acesso ao Ensino Superior dessa população, ainda existem desafios que por ora obstaculizam o acesso à universidade, como a realidade fronteiriça de índices de formação baixos, conectados a um imaginário que afasta parte dessas pessoas do meio acadêmico que foi criado com o objetivo principal de alcançar essas populações.

Palavras-chave Universidade - Comunidade - Acesso ao Ensino Superior.

\begin{abstract}
The present article is a field research produced in the city of Jaguarão/RS on the views of the community in relation to the Federal University of Pampa - Campus Jaguarão. Thus, a case study was developed during 2018 in the peripheral neighbourhoods surrounding the university. Through a questionnaire, sixty-six people were interviewed. With these interviews, a data analysis was produced that suggests the type of relationship that this community has with the university. The data indicate that despite the positive impact of the institution, considered one more element for access to higher education for this population, there are still challenges that hinder access to university for now, such as the border reality of low training rates, connected to a imaginary that separates part of these people from the academic environment created with the main objective of reaching these populations.
\end{abstract}

Keywords University - Community - Access to Higher Education.

\section{Submissão}

$16 / 02 / 2020$

\section{Aprovação}

03/IO/2O2O
Publicação

$30 / 12 / 2020$ 


\section{Introdução}

$\mathrm{E}$ sta pesquisa foi desenvolvida no Programa de Educação Tutorial - Pedagogia durante o ano de dois mil e dezoito, e busca mapear quais são as visões da comunidade local domiciliada no entorno da Universidade Federal do Pampa (Unipampa), especificamente no Campus Jaguarão, sobre a instituição de ensino que fixou território físico ao construir sua sede no bairro Vila Kennedy, na periferia da cidade de Jaguarão/RS.

Resultado de muitas reivindicações da comunidade que reside nas regiões de fronteira do estado, e principalmente dos moradores da "metade sul” do Rio Grande do Sul, a Unipampa surgiu com o dever de cooperar com a região em que está inserida - um território extenso, marcado pelas fronteiras com a Argentina e o Uruguai, e consideráveis problemas na área da educação e no desenvolvimento socioeconômico junto a uma demanda por maior acesso dessas populações à Educação Básica e Superior.

O reflexo desse cenário socioeconômico e político é que pessoas oriundas dessas zonas tinham a obrigatoriedade, caso desejassem cursar o Ensino Superior, de deslocar-se para as cidades maiores do Rio Grande do Sul, como Pelotas, Rio Grande ou até Porto Alegre, criando um êxodo e hiato na faixa etária mais jovem dessas populaçóes locais para outras regiões. ${ }^{\text {I }}$

Nesse contexto mencionado acima, o município de Jaguarão se apresenta como uma síntese deste cenário: localizado na microrregião da zona sul do estado do Rio Grande do Sul, possui uma população de 27.93I pessoas (IBGE, 20IO), porém, mesmo com o segundo maior PIB per capita desta microrregião, teve uma estimativa populacional em 2019 de 26.680 ; no ano 2000, o censo apontou 30.093, o que nos sugere um encolhimento populacional que vai além da presença ou não da universidade no município. ${ }^{2}$

A cidade está localizada às margens do rio Jaguarão, que divide a fronteira entre Brasil e Uruguai, além de estar na faixa de fronteira de I5o km estabelecida pela Lei no 6.634/1979, sendo considerada área indispensável à segurança nacional - devido a política de segurança nacional que envolve esta lei federal, oriunda do regime militar, há um abismo para estes municípios no que se refere a instalação de indústrias, estruturas como estradas, pontes, dentre outras que sejam de alguma forma entendidas como de “interesse nacional” (Art. $2^{\circ}$ ). ${ }^{3}$

I BRASIL, IBGE. Jaguarão - RS - IBGE Cidades. Brasília: 20IO - 20I8. Disponível em: «https://cidades.ibge.gov.br/brasil/rs/jaguarao/panorama». Acesso em: I7 de dezembro de 2019.

2 BRASIL, IBGE. Jaguarão - RS - IBGE Cidades. Brasília: 2oro - 2or8. Disponível em: «https://cidades.ibge.gov.br/brasil/rs/jaguarao/panorama». Acesso em: I7 de dezembro de 2019.

3 BRASIL. Lei da Faixa de Fronteira. 1979. Disponível em: «https://www2.camara.leg.br/legin/fed/lei/1970-1979/lei6634-2-maio-1979-365762-norma-pl.html». Acesso em: 17 de dezembro de 2019.

$62 \cdot$ ano XI, n. 16, $2020 \cdot$ ISSN 2179-5487 
Imagem I: Mapa da cidade de Jaguarão, a Unipampa está localizada na região em amarelo.

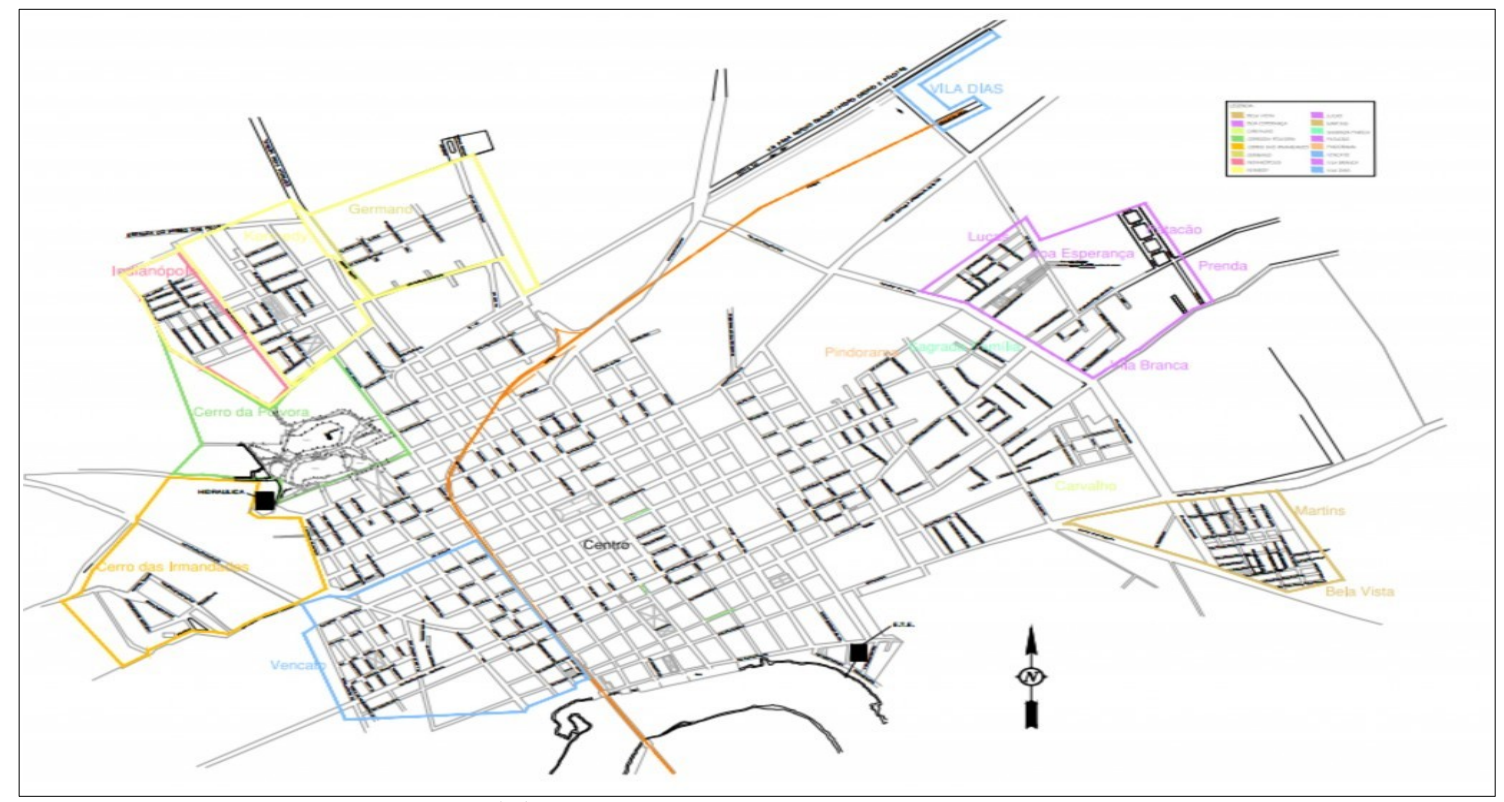

Fonte: Prefeitura Municipal de Jaguarão, 2020.

Em decorrência de tal lei, grande parte das indústrias não se instalaram nesses espaços territoriais, o que interferiu indiretamente no desenvolvimento dos municípios, já que, conjuntamente com a distância relativa de grandes centros microrregionais e principalmente estaduais, como Rio Grande, Porto Alegre e Santa Maria, produziram-se limitações ao desenvolvimento local, caracterizado em torno da produção de alimentos monopolizada por poucos latifundiários do agronegócio.

Deste cenário específico houve, em certa medida, um isolamento dessas populações, que ficaram deficitárias de acesso a direitos sociais, como uma educação superior pública e gratuita. A ausência de políticas públicas que levassem em consideração os habitantes de tais cidades isoladas, principalmente no âmbito da educação, deixaram os municípios no que podemos denominar como um atraso temporal-educacional.

O reconhecimento destas condições que permeavam - e ainda permeiam - estas regióes, juntamente às demandas provenientes da sociedade civil de ampliar a oferta do Ensino Superior gratuito e de qualidade, mobilizaram os gestores dos municípios que hoje se localizam na área de abrangência da Unipampa a pleitear, junto ao Ministério da Educação (MEC), a criação de uma instituição federal de Ensino Superior. A partir de uma extensa mobilização, foi anunciado no dia 27 de julho de 2005 , o atendimento a este pleito em um ato público na cidade de Bagé/RS, com a presença do então presidente Luiz Inácio Lula da Silva.

Nesta mesma ocasião foi anunciado o Consórcio Universitário da Metade Sul, através de um acordo de cooperação técnica financiado pelo MEC, com a Universidade Federal de Santa 


\section{REVISTA ANGELUS NOVUS}

Maria (UFSM) e a Universidade Federal de Pelotas (UFPEL), com início das atividades em setembro de 2006. O mencionado acordo técnico integrava o programa de Reestruturação e Expansão das Universidades Federais (REUNI), que também trouxe para a cidade o Instituto Federal Sul-Rio-Grandense.

$\mathrm{Na}$ cidade de Jaguarão/RS, a universidade utilizou o prédio do extinto Colégio de Freiras Imaculada Conceição, localizado no centro da cidade, como prédio provisório até a inauguração de seu prédio oficial, que ocorreu no ano de 2010 e localiza-se no bairro Kennedy. E, a partir disto, muitas dúvidas cercavam a comunidade, inclusive se os cursos seriam pagos ou não, ou até mesmo se a instituição conseguiria permanecer na cidade por muito tempo, dúvidas estas que eram levadas à imprensa local, principalmente aos programas de rádio.

É importante citar alguns apontamentos sobre os distanciamentos simbólicos da universidade, como o de que o sistema universitário é marcado por vozes e culturas brancas, que historicamente excluíram os subalternos da academia ${ }^{4}$; e também a proposta de uma transição de conhecimentos proposta por Santos', do universitário ao pluriversitário, que se pauta a partir da ecologia dos saberes. Dentro deste contexto social, este trabalho objetiva analisar as visóes e dúvidas da comunidade sobre a universidade, e se a comunidade tem mantido uma relação de proximidade ou distância com a universidade que se instalou no seu entorno.

Tais objetivos apoiam-se nos seguintes fatores: há muitas pessoas - em sua maioria jovens - que viajam cerca de $280 \mathrm{~km}$ diariamente para estudarem em universidades públicas e privadas na cidade de Pelotas/RS, ou que param seus estudos após a conclusão da Educação Básica; nas vivências dentro da escola - e no que muito se ouve durante o terceiro ano do Ensino Médio - percebe-se que há um discurso recorrente de que a Unipampa é uma universidade para "quem não teve outra opção" ou "para quem não conseguiu nota para ingressar na UFPEL", o que demonstra que tal espaço social e territorial exprime pequenas hierarquias e distâncias sociais de forma simbólica. ${ }^{6}$ Além disso, após dez anos da chegada de uma instituição pública de Ensino Superior ao município, ainda existem questionamentos sobre o que a mesma traz de relevante para a cidade e, também, se são todos que podem ingressar sem pagar.

A partir destes fatores, a pesquisa tem a seguinte problemática: quais são as visões que a comunidade presente no entorno da universidade possui sobre esta e qual a relevância desta instituição de ensino no cotidiano da comunidade? Tem-se como hipótese que, a pequenos passos, a comunidade acolhe a universidade apenas quando possui algum tipo de vínculo que

4 KILOMBA, Grada. Memórias da plantação: episódios de racismo cotidiano. Rio de Janeiro: Cobogó, 2019.

5 SANTOS, Boaventura de Sousa. A universidade no século XXI: para uma reforma democrática e emancipatória da universidade. São Paulo: Cortez, 20II.

6 BOURDIEU, P. Efeitos do Lugar. In: BOURDIEU, P. (Org.). A miséria do mundo. Petrópolis: Vozes,1997. p. I59-175.

$64 \cdot$ ano XI, n. 16, 2020 • ISSN 2179-5487 
faça parte de seu cotidiano, seja como estudante, servidor, integrante de algum projeto ou conhecendo alguém que esteja dentro destas condições.

Além disso, nota-se que a aceitação das instituições que se estabeleceram há pouco tempo também está ligada a ideia de que os estudos levam à ascensão social. Como é dito de forma recorrente nas apresentações dos alunos ingressantes no início dos componentes curriculares: “estudar para conseguir um emprego melhor” ou “para ser alguém na vida”. Para Goergen, estes discursos têm explicação:

Mesmo sendo fonte de todo o processo de hominização desde os primórdios de nossa espécie, o conhecimento nunca esteve tão estreitamente atrelado ao exercício do domínio e do poder quanto hoje. Tornou-se condição de acesso ao trabalho e de sobrevivência. Quanto mais conhecimento, melhores as perspectivas de desenvolvimento e ascensão social.7

A escolha por esta temática, que integra o campo de estudos sobre o Ensino Superior, surgiu através de diálogos da pesquisadora com pessoas que não possuíam algum tipo de vínculo com a Unipampa. Observou-se que havia dúvidas sobre o processo seletivo para o ingresso na universidade, desconhecimento sobre a existência de alguns cursos, funcionamento das bolsas (programas de permanência, programas de incentivo à pesquisa, ensino e extensão) e também sobre a possibilidade de conciliar a rotina de estudos com a jornada de trabalho que, em geral, consiste em oito horas diárias, além de discursos frequentes sobre a Unipampa, como se fosse uma universidade que apenas "fabrica diplomas" ou que só traz perturbações para a cidade.

Nestas perspectivas, é relevante relembrar o caso da Rede Pampa de Porto Alegre/RS, onde em um determinado programa televisivo, alguns apresentadores reuniram-se para apontar supostos problemas da Unipampa e discutir sobre a utilidade da universidade, degradando os cursos de graduação que foram implantados na cidade, questionando a formação dos professores e a validade da mesma, bem como suas aparências físicas e, de certa maneira, a credibilidade da instituição. Cabe ressaltar que, replicados de forma recorrente, tais discursos da mídia podem vir a formar uma opinião massificada e contribuem para a construção de uma imagem distorcida sobre a instituição. ${ }^{8}$

O cenário da Educação Superior em Jaguarão é composto por uma universidade pública, um instituto federal e três instituições de ensino superior privado. A universidade pública conta com seis cursos, sendo quatro licenciaturas, um tecnólogo e um bacharelado, o instituto federal com dois cursos técnicos e um subsequente, e as instituições privadas possuem cursos

7 GOERGEN, Pedro. “Tecnociência, pensamento e formação na educação superior”. In: Avaliação, Campinas: Sorocaba, SP, v. 19, n. 3, p. 562.

8 Disponível em: «https://Unipampa.edu.br/portal/Unipampa-divulga-nota-de-esclarecimento-sobre-programapampa-debates». 


\section{REVISTA ANGELUS NOVUS}

privados nas oito grandes áreas do conhecimento, na modalidade à distância e semipresencial, com um destaque maior nos cursos da área de Ciências da Saúde.

A partir disso, desenvolveu-se uma pesquisa de campo que ocorreu durante o mês de abril de 20I8, contabilizando um total de cinquenta e duas pessoas entrevistadas, com dados colhidos através de um questionário que havia sido elaborado durante os últimos três meses de 2017.

\section{Metodologia}

Trata-se, sinteticamente, de um estudo de caso sobre as percepções da comunidade local acerca do impacto que a universidade alcança ao estar instalada em torno das suas residências e naquele município. Sendo assim, esta investigação pode ser definida como um estudo sobre uma entidade bem definida, como uma instituição, um programa, um sistema educacional, uma unidade social ou uma pessoa, e que também visa conhecer em profundidade o como e o porquê de uma determinada situação que se pressupõe ser inédita em muitos pontos, buscando descobrir o que há nela de mais característico e essencial. ${ }^{9}$

Utilizou-se uma metodologia qualitativa, com a coleta de dados através da realização de uma pesquisa de campo, em que foram aplicados o total de sessenta e seis questionários entre os bairros Kennedy, Indianópolis I e Indianópolis II, que ficam nas redondezas do Campus Jaguarão, alcançando um público na faixa etária de I8 a 7I anos, tendo como objetivo geral conhecer e compreender as visões que tais indivíduos possuem acerca da universidade. De acordo com Severino: "Na pesquisa de campo o objeto/fonte é abordado em seu meio ambiente próprio. A coleta dos dados é feita nas condições naturais em que os fenômenos ocorrem, sendo assim diretamente observados, sem intervenção e manuseio por parte do pesquisador”. ${ }^{10}$

No total, o questionário conta com treze perguntas, que buscam saber se os respondentes possuem algum tipo de vínculo direto com a Unipampa (seja na graduação, pósgraduação, formação continuada ou participando de atividades de extensão), qual sua faixa etária, sexo, escolaridade e quais mudanças a universidade trouxe para a região e para a sua vida pessoal, classificando estas mudanças como positivas ou negativas.

Após a coleta, para a verificação destes dados, utilizou-se a metodologia de análise textual discursiva ${ }^{\text {II }}$ tendo a intenção - antes de refutar ou comprovar hipóteses - de

9 FONSECA, J. J. S. Metodologia da pesquisa cientifica. Fortaleza: UEC, 2002.

Io SEVERINO, Antônio Joaquim. Metodologia do trabalho cientifico. São Paulo: Cortez, 2007, p. II8.

II MORAES, Roque. “Uma tempestade de luz: a compreensão possibilitada pela análise textual discursiva”. In: Ciência Ë Educação, v. 9, n. 2, p. 19I-2II, 2003.

$66 \cdot$ ano XI, n. I6, $2020 \cdot$ ISSN 2179-5487 
compreender o fenômeno a ser estudado, estabelecendo as relações entre unidades fragmentadas de dados para construção de conjuntos mais complexos que possam ser categorizados para produção de uma compreensão renovada de nossos objetos e sujeitos de pesquisa. Para isto, foi utilizado o programa $P S P P$, para a organização e posterior análise dos dados. Nesse sentido, esse trabalho foi produzido por meio das seguintes etapas:

Quadro r: Processo de produção desta pesquisa.

\begin{tabular}{|l|l|}
\hline I. Etapa & Revisão bibliográfica e elaboração de instrumentos de pesquisa \\
\hline 2.․ Etapa & $\begin{array}{l}\text { Mapeamento preliminar dos bairros localizados próximo a sede } \\
\text { da Unipampa para a coleta de dados }\end{array}$ \\
\hline $3 \cdot$ - Etapa & $\begin{array}{l}\text { Aplicação de questionário de pesquisa nessas regiões do } \\
\text { município }\end{array}$ \\
\hline $4 \cdot$ - Etapa & $\begin{array}{l}\text { Estruturação de Bancos de Dados, análise e discussão dos } \\
\text { questionários }\end{array}$ \\
\hline
\end{tabular}

Fonte: Elaborada pela autora, 2019.

A discussão foi embasada nos resultados obtidos e, a partir deles, pretende-se desenvolver uma análise sobre quem são estes respondentes e quais suas visões sobre a Unipampa. Também pretende-se realizar uma discussão teórica da relação de proximidade e distanciamento entre a universidade e a sociedade, mencionado anteriormente, e quais os impactos sociais do distanciamento.

\section{Resultados e discussão}

Ao realizar a aplicação dos formulários com os indivíduos foi possível observar, primeiramente, que grande parte dos respondentes não possuía nenhum tipo de vínculo com a universidade. Nesse sentido, $83, \mathrm{I} \%$ dos sujeitos de pesquisa disseram não possuir nenhuma ligação com a instituição, apenas $16,9 \%$ possuíam algum vínculo.

Em certa medida esses dados se justificam pelo contexto social marginalizado dessas populações relativamente distantes de áreas centrais do município, nas quais os serviços com maior qualidade se concentram, assim como pela média de idade dos (as) pesquisados (as), 


\section{REVISTA ANGELUS NOVUS}

que foi de 39,67 anos, muitos dos quais não tiveram oportunidade de concluir a educação básica ou acessar o Ensino Superior.

Gráfico I: Nível de escolaridade dos entrevistados, em números absolutos.

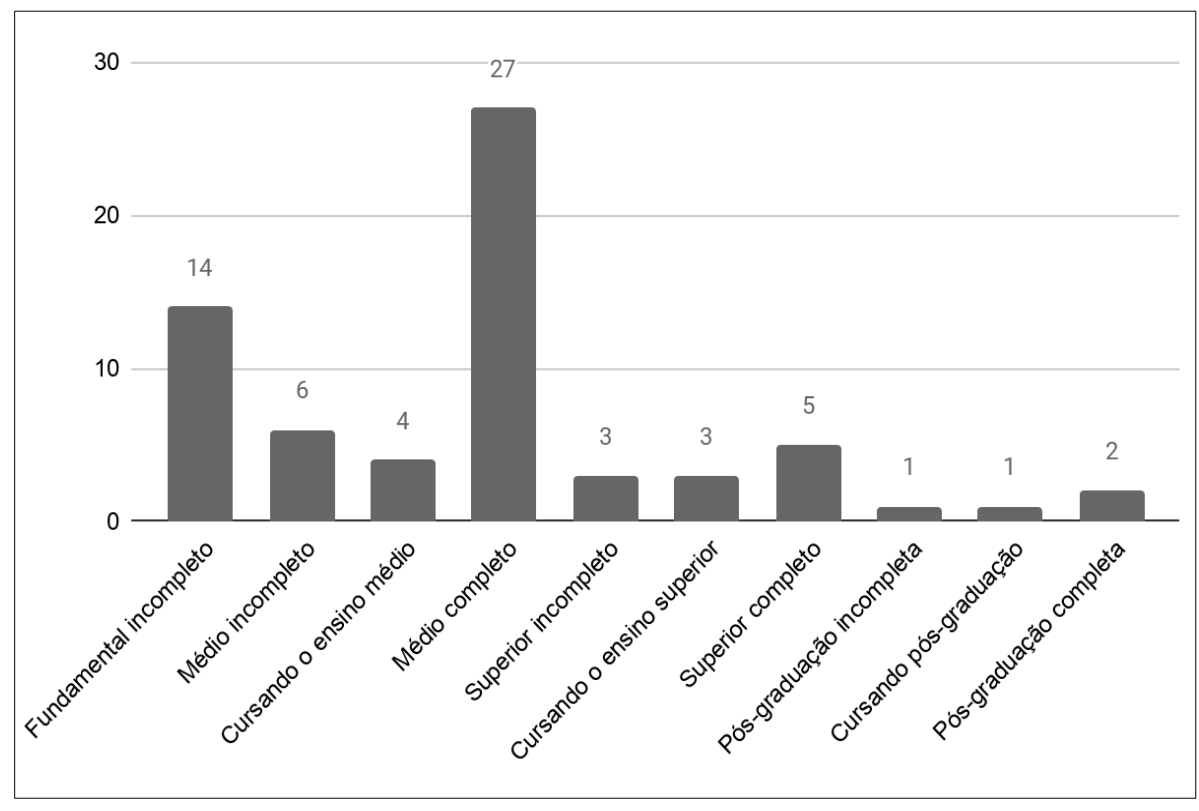

Fonte: Elaboração da autora com dados da pesquisa de campo, 2018.

A maior parte dos entrevistados possui ensino médio completo - 40,9\%, seguida de 2I,2\% com ensino fundamental incompleto. Apenas 22,7\% dos entrevistados conseguiram alcançar o ensino superior, contando nesse cenário não apenas aqueles (as) vinculados (as) à Unipampa-Jaguarão, mas analisando o acesso de forma ampla.

Apesar de uma amostra reduzida em 16 sujeitos de pesquisa, ao analisarmos a escolaridade pelo recorte dos jovens de I8 a 24 anos, $25 \%$ declararam estar com o Ensino Fundamental incompleto e $12,5 \%$ com Ensino Médio incompleto - este número aumenta quando desconsideramos o recorte por faixa etária, pois 9,1\% do total de entrevistados declaram a escolaridade de Ensino Médio incompleto.

Ao analisarmos cumulativamente categorias que contemplam Ensino Fundamental e Médio, temos um acúmulo de 81,3\% de jovens fora do Ensino Superior, montante também maior quando analisamos a escolaridade do total de pesquisados (as), assim, apenas 19,7\% dos jovens entre I8 a 24 anos que participaram da aplicação do questionário estavam/estiveram no Ensino Superior.

A título de comparação, de acordo com Pesquisa Anual por Amostra de Domicílios Contínua (PNAD-Contínua) de 2018 , 25,2\% dos jovens entre I8 a 24 frequentavam ou haviam 
terminado algum curso em nível superior, e apenas II\% estavam atrasados, cursando a Educação Básica. ${ }^{12}$

Dentre os sujeitos entrevistados que acessaram o Ensino Superior, 66,7\% possuíam vínculo com a Unipampa, seja nos cursos de graduação, pós-graduação ou formação continuada, demonstrando a relevância da instituição para o ingresso na educação superior na região. O que esses dados nos sugerem é que, apesar da baixa escolaridade quando comparada a parâmetros nacionais, cumpre ainda à instituição um papel de acesso aos que vivem nas redondezas.

Ao serem perguntados (as) sobre a relevância da instalação do campus da instituição, $84,6 \%$ concordam que é relevante para a comunidade ter em seu município uma universidade pública. Porém, quando questionada a relevância da instituição na vida pessoal dos (as) pesquisados (as), 57,6\% afirmaram não ser importante para as suas trajetórias de vida a instalação da instituição, ou seja, os dados nos fazem perceber que a comunidade, apesar de entender a importância de uma Instituição de Ensino Superior na sua localidade, paradoxalmente, por algum contexto, não consegue ter acesso ou não a procura. Para Ferrari: "Quando as relações sociais não são transformadas, independentemente da forma que assuma a sua representação e abordagem, lugares hierarquizados persistem e a mudança de termos só oculta a permanência de uma velha ordem". ${ }^{\text {33 }}$

Levando em consideração os bairros que fizeram parte desta pesquisa e que cercam a universidade, podemos questionar os motivos pelos quais estas pessoas não participam das atividades realizadas pela instituição. Seriam falhas na comunicação e divulgação das atividades por parte dos professores, técnicos e discentes ou desinteresse dos moradores do local? Como ponto de partida para pensar estes distanciamentos da comunidade com a universidade, é importante o apontamento de Goergen:

O que significa ter acesso à educação é, sem dúvida, uma questão nada fácil de ser respondida no contexto da sociedade contemporânea. Se até algumas décadas atrás ainda existiam razoáveis consensos em termos de estrutura e organização social, de valores e de formas de comportamento que serviam de orientação para o processo educativo, atualmente até estes paradigmas mínimos se desestabilizaram. ${ }^{14}$

Este trabalho de campo sugere algumas respostas às questões apresentadas.

BRASIL, IBGE. Pesquisa Anual por Amostra de Domicílios Contínua (PNAD-Contínua). 20I8. Disponível em: «https://www.ibge.gov.br/estatisticas/multidominio/condicoes-de-vida-desigualdade-e-pobreza/1727o-pnadcontinua.html?=\&t=o-que-e». Acesso em: Is de dezembro de 2019.

I3 FERRARI, Rogério. "A universidade e o círculo fechado: sobre o erro da razão na etnografia". In: Revista Sures. n.II, p. I-19, 2013, p. IO.

I4 GOERGEN, Pedro. "A educação como direito de cidadania e responsabilidade do Estado". In: Revista Educação e Sociedade, vol.34, n. I24, p. 733 . 
Gráfico 2: Relação entre o tipo de impacto percebido pela instalação da universidade dividido por nível de ensino.

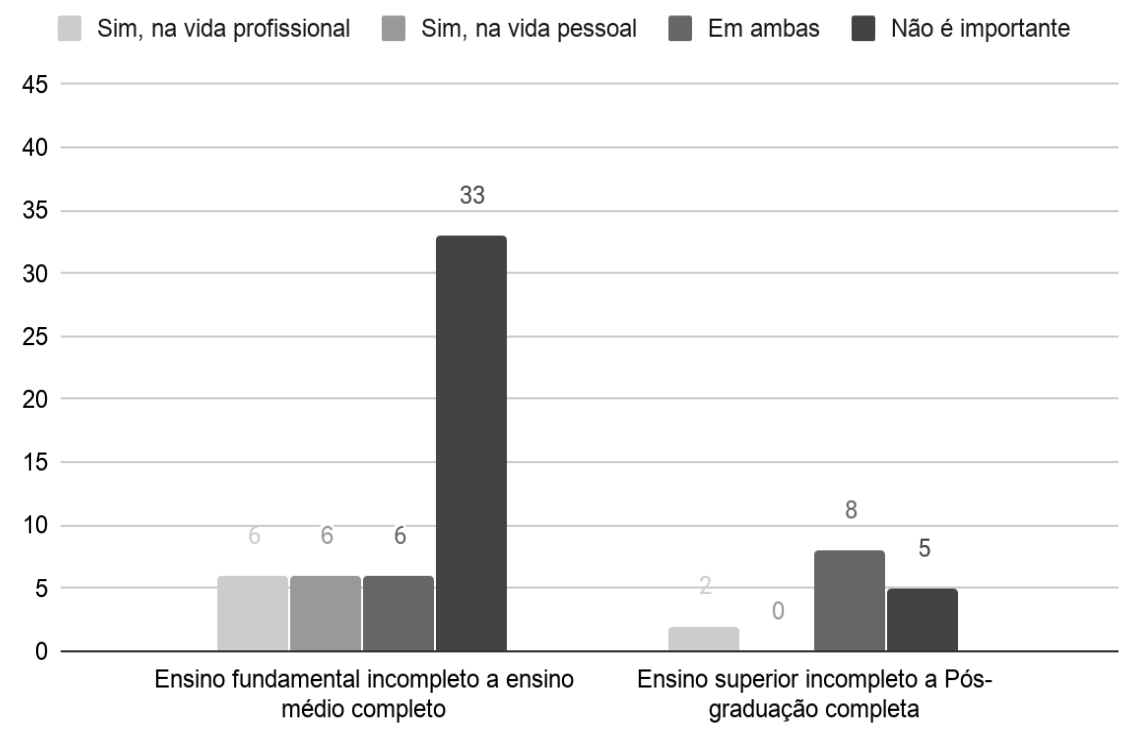

Fonte: Elaboração da autora com dados da pesquisa de campo, 2018.

No Gráfico 2, ao dividirmos os (as) pesquisados (as) em duas categorias de análise, identificamos uma maior rejeição por parte daquele grupo com menor escolarização; nesse sentido, 64\% afirmaram não ser importante o impacto da universidade contra apenas $33 \%$ entre aqueles (as) que tiveram a oportunidade de acesso universitário.

$\mathrm{Na}$ faixa daqueles (as) que não acessaram o ensino superior e afirmaram não achar importante o impacto da instituição, destaca-se que $31 \%$ estavam com o Ensino Fundamental incompleto, $19 \%$ com o Ensino Médio incompleto e $4 \mathrm{I} \%$ com o Ensino Médio completo, porém sem acesso ao Ensino Superior.

Entretanto, quando olhamos para cada faixa escolar na intenção de identificarmos o nível de concordância e discordância do impacto e importância da instituição, percebemos que a maior rejeição está naqueles (as) com Ensino Médio incompleto com 6 registros (Ioo\%); seguido de Ensino Fundamental incompleto (77\%) e cursando o Ensino Médio (75\%); há uma significativa diminuição apenas naqueles (as) com Ensino Médio completo com I3 registros cada (50\%) em visões positivas e negativas da instituição.

Percebe-se pelos dados trazidos até aqui que o abandono escolar é um elemento relevante na hora de se produzir um imaginário sobre a importância da universidade na sociedade, pois os dados nos indicam que esse distanciamento/trauma escolar gera nesse grupo uma maior resistência para a produção de opiniões mais consistentes sobre o papel que possui a

$70 \cdot$ ano XI, n. I6, $2020 \cdot$ ISSN 2179-5487 
universidade na comunidade. Porém, sabe-se que tais dados não representam a totalidade de um pensamento da comunidade, pois muitos discentes - se não a maioria - são provenientes das classes populares, incentivados pelas famílias a prosseguirem os estudos, contribuindo diretamente para o sucesso escolar e acadêmico. ${ }^{15}$

Quando se analisa mais profundamente aqueles (as) que estão/estiveram no Ensino Superior, percebe-se que os (as) que identificaram impactos positivos foram justamente aqueles (as) com algum vínculo com a instituição. O primeiro dado que chama a atenção é que dos cinco registros de pessoas que alcançaram o Ensino Superior e que não percebem como importante o impacto da instituição, quatro eram oriundos de outras instituições e sem trajetória pessoal na Unipampa. Assim, nesse cenário, podemos presumir que por serem pessoas que por outras vias obtiveram acesso à universidade, percebem a instalação do campus como irrelevante aos seus objetivos e, por consequência, apontaram pontos negativos.

$\mathrm{Na}$ contramão dos dados supracitados, para aqueles (as) com algum vínculo com a Unipampa, identificou-se dois registros que compreendem a instituição e seu impacto na vida profissional e oito casos em que impactavam conjuntamente o âmbito profissional e vida pessoal. Desses sujeitos vinculados à instituição, podemos destacar que aqueles (as) que já possuem graduação ou pós-graduação completa na instituição somaram 50\% dos registros positivos da instalação da Unipampa. Assim, desta realidade, podemos destacar três afirmações: que o acesso à universidade é importante para a criação de um imaginário positivo da instituição; que o mero acesso por outras instituições de Ensino Superior não foi o suficiente para que estes sujeitos dessem valor à instituição local - visto que frequentaram instituições privadas e localizadas em outras cidades; e que esta visão de impacto surge com maior potência naquelas pessoas com alguma vinculação ou trajetória institucional na Unipampa.

Durante a pesquisa de campo, quando questionados (as) os (as) entrevistados (as) se a vinda da Unipampa para a cidade teria sido um acontecimento relevante, assim como qual a importância que a instituição possui na vida dos mesmos, alguns dos respondentes disseram que a instituição é relevante, mas que a IES (Instituição de Ensino Superior) poderia ofertar mais cursos.

Dentre alguns dos relatos e questionamentos ouvidos durante a pesquisa de campo, como o de "que não há nenhum curso que dê dinheiro", "os cursos não nos permitem seguir residindo na cidade”, “já estudei lá e foi muito difícil, muita coisa para ler” e “os cursos só formam professores, e quem não quer ser professor?”. O fato dos cursos de licenciatura na área de Humanas serem desprestigiados socialmente, somado aos ataques e a própria 


\section{REVISTA ANGELUS NOVUS}

uberização da docência, promove o que Martins ${ }^{16}$ chama de "inclusão marginal”, que permite o maior acesso das classes populares à universidade apenas nos cursos que são vistos como fáceis ou sem utilidade pelo senso comum vigente.

No país onde a universidade é peça do dispositivo de domínio das classes das camadas sociais espoliadoras, a autonomia universitária revela-se sempre nociva aos interesses do povo, pois ajuda, mediante as ficções jurídicas que engendra, a manter distante do controle social, pelas massas trabalhadoras, esse instituto, que se julga entidade à parte..$^{77}$

Pensar sobre a autonomia universitária e reivindicá-la é essencial, mas também é questionável qual o impacto desta autonomia quando - ou se - entra em contato com a comunidade externa, e principalmente, as classes populares. Ao abordar sobre o aluno proveniente das classes populares, diz o mesmo autor:

O aluno pobre, que cursou colégios suburbanos, onde os professores são com frequência menos eficientes, em virtude da pobreza e da má remuneração, os estudantes que trabalham durante o dia e só dispuseram de poucas e cansadas horas para estudos à noite, esses evidentemente se apresentarão "mal preparados", mas esses são os verdadeiros elementos do povo, os filhos de trabalhadores, trabalhadores eles próprios, que se vêem expulsos da faculdade pelo crime de serem pobres e não se mostrarem tão capazes nas sibilinas, ridículas e antipedagógicas provas a que são Submissãos. ${ }^{18}$

Sendo assim, a forma de ingresso e até de permanência estabelecem um fogo de barragem “(...) a fim de conter a bala, a metralha, o assalto das massas que desejam ocupar a cidadela do saber.” ${ }_{19}$ A partir destes apontamentos, é possível pensar em uma universidade popular? Com quais tipos de impasses, além dos que já conhecemos? Como construir uma universidade popular se as avaliações que regulam quem entra são excludentes?

Ao pensar em uma instituição emergente como a Unipampa, que é composta em sua grande maioria por trabalhadores, pessoas que possuem dupla ou tripla jornada, e em que de sete cursos, seis são presenciais, poucas vezes são vistas atividades no período do curso que possam envolver os alunos com ensino, pesquisa e extensão, além das aulas inaugurais e dos trabalhos de pesquisa propostos durante os componentes curriculares. Ao olhar brevemente para os Projetos Políticos Pedagógicos, nota-se que, cada curso possui, no máximo, dois ou três componentes curriculares que abordam a pesquisa em suas respectivas áreas. Fazer essa crítica não desmerece o que os cursos já vêm produzindo, mas apoia-se na ideia de que a universidade pode alterar suas maneiras de ser e pensar, assim como sua postura crítica também se modifica e amadurece. ${ }^{20}$

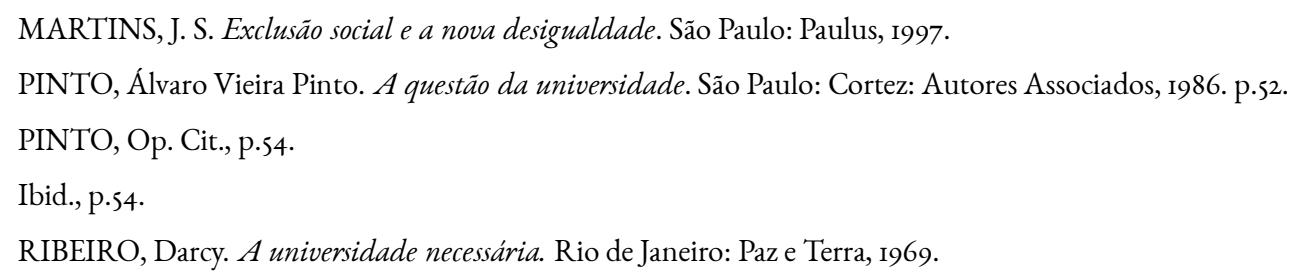


Neste sentido, parece haver um entendimento da comunidade externa de que o Campus Jaguarão apenas forma professores, o que é um equívoco sobre a instituição e as possibilidades dos cursos oferecidos, que são quatro licenciaturas - Pedagogia, História, Letras - Português e Literaturas de Língua Portuguesa, Letras - Espanhol e Literatura Hispânica, Letras Português/Espanhol e Respectivas Literaturas; um Tecnólogo em Gestão de Turismo e um Bacharelado em Produção e Política Cultural. Há um curso institucional de educação à distância (EAD) de Licenciatura em Letras - Português, além dos cursos de Licenciatura em Letras - Português e Pedagogia - Licenciatura, ofertados pela Universidade Aberta do Brasil (UAB).

Apesar da oferta de cursos presenciais e EAD, percebe-se nos discursos que permeiam o imaginário sobre a Unipampa, a ideia de que a universidade poderia oferecer mais cursos em outras áreas. Nesse sentido, no ano de 2019 circulou um abaixo-assinado pela vinda dos cursos de Direito, Ciências Contábeis, Administração e Medicina Veterinária, que poderiam atender uma gama maior de interesses formativos.

As críticas recorrentes dos entrevistados às licenciaturas indicam as possíveis desvalorizações que permeiam o campo da formação docente, como os baixos ganhos salariais, o status da profissão docente ser "o que sobrou” e até uma relação hierárquica entre as profissões. Genro et. al. ${ }^{21}$, nos dá um possível panorama de tais ideias sobre o Ensino Superior em disputa dentro dos contextos neoliberais: de um lado, a exigência de uma formação a serviço do mercado, de outro, a não disposição das pessoas a dedicarem suas formações para serem empreendedores.

Ao analisar se os respondentes possuíam vínculo com a IES, 83,1\% afirmou não ter nenhum tipo de vínculo, e I6,9\% possuiu algum tipo de vínculo. A questão direcionada sobre quando os entrevistados tiveram conhecimento sobre a fundação da Unipampa, teve os seguintes índices: $51,5 \%$ após a implantação de seu prédio oficial no Bairro Kennedy, 33,3\% no ano de sua criação, I2,I\% após a formatura de um amigo/parente dentro da instituição e 3\% após disputar uma vaga no Sistema de Seleção Unificada (SISU).

Percebe-se uma assimetria entre a primeira e a última resposta, pois se grande parte dos sujeitos tiveram conhecimento sobre a universidade após a implantação de seu prédio oficial, cabe pensarmos sobre o por que apenas $3,0 \%$ concorreu a uma vaga no SISU e se os mesmos veem a universidade como um espaço que é seu por direito e sabem dos auxílios, projetos e programas que a mesma oferece. Segundo Boaventura de Sousa Santos, "A universidade pública deve permanecer gratuita e aos estudantes das classes trabalhadoras devem ser

2I GENRO, M. E. H; MAFFEI, H. S.; CAVALCANTE, M. H. K. “Universidade emergente: integração latino-americana e a contribuição da UNILA”. In: Revista Sures, n.II, p. I-I9, 2013. 


\section{REVISTA ANGELUS NOVUS}

concedidas bolsas de manutenção e não empréstimos”. ${ }^{22}$ Sabe-se que essas bolsas de manutenção são concedidas, como o Programa Nacional de Assistência Estudantil (PNAES), que dispõe de recursos como o auxílio-moradia, o auxílio-alimentação, o auxílio-transporte e o auxílio-creche, o Programa de Apoio ao Ingressante, o Programa de Desenvolvimento Acadêmico (PDA), que abre um edital anual para o fomento de bolsas para projetos de ensino, pesquisa e extensão, e o Programa de Apoio à Participação Discente em Eventos (PAPE).

Considera-se que ter uma formação educacional, de qualquer tipo, é de suma importância tanto para a formação pessoal quanto para a profissional. De acordo com o Programa de Desenvolvimento Institucional (PDI - 2009-2013), a universidade deve contribuir da seguinte maneira:

A Unipampa exercerá seu compromisso com o seu ao-redor, por meio de atividades de ensino de graduação e de pós-graduação, de pesquisa científica e tecnológica, de extensão e assistência às comunidades e de gestão. Para que tais atividades ganhem em efetividade e relevância, a Universidade deverá defini-las a partir do conhecimento da realidade da região, em diálogo pleno com os atores que a constroem..$^{23}$

Mesmo com estes programas que visam auxiliar o discente em sua permanência dentro da instituição, de acordo com o relatório de gestão do campus, entre 2014 e 20I6, houve um total de $39 \%$ entre abandono e trancamentos de matrícula nos cursos, que tiveram o total de 1374 ingressantes. Neste mesmo período, o curso de História - Licenciatura apresentou um maior número de abandono e trancamento, com o número de 22I matrículas; o curso de Pedagogia - Licenciatura com 139, Licenciatura em Letras - Português, Espanhol e Respectivas Literaturas (diurno e noturno) com I49; Tecnólogo em Gestão de Turismo com II8; e o Bacharelado em Produção e Política Cultural com 94. 
Gráfico 3: Relação entre gênero e tipo de mudanças no município após a instalação da Unipampa.

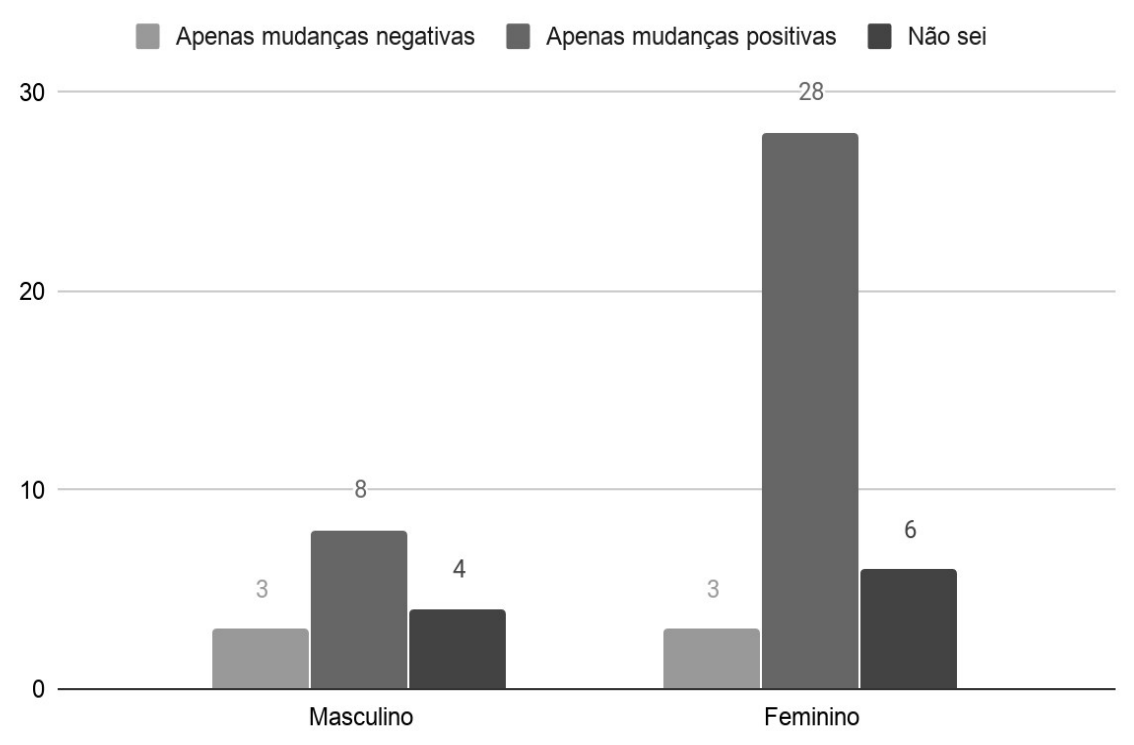

Fonte: Elaboração da autora com dados da pesquisa de campo, 2018.

Ambos os gráficos $(3$ e 4$)$ se referem à relação entre os gêneros e suas percepções das mudanças que a universidade trouxe. No questionário, classificamos como positivas ou negativas, mas ao produzirmos as análises, consideramos que nos faltavam elementos para elencar o que seriam tais divisões, pois os conceitos podem ser, e muitas vezes são, bastante subjetivos. Assumimos as categorias elencadas enquanto falha no percurso de pesquisa, o que acontece de forma recorrente na formação do professor-pesquisador.

O primeiro gráfico refere-se a uma avaliação genérica entre o entendimento que os entrevistados tinham sobre as tais mudanças; logo, o segundo gráfico apresenta um cruzamento entre gênero e como estes percebem as mudanças após a instalação da universidade. 
Gráfico 4: Relação entre gênero e percepção das mudanças no município após a instalação da Unipampa.

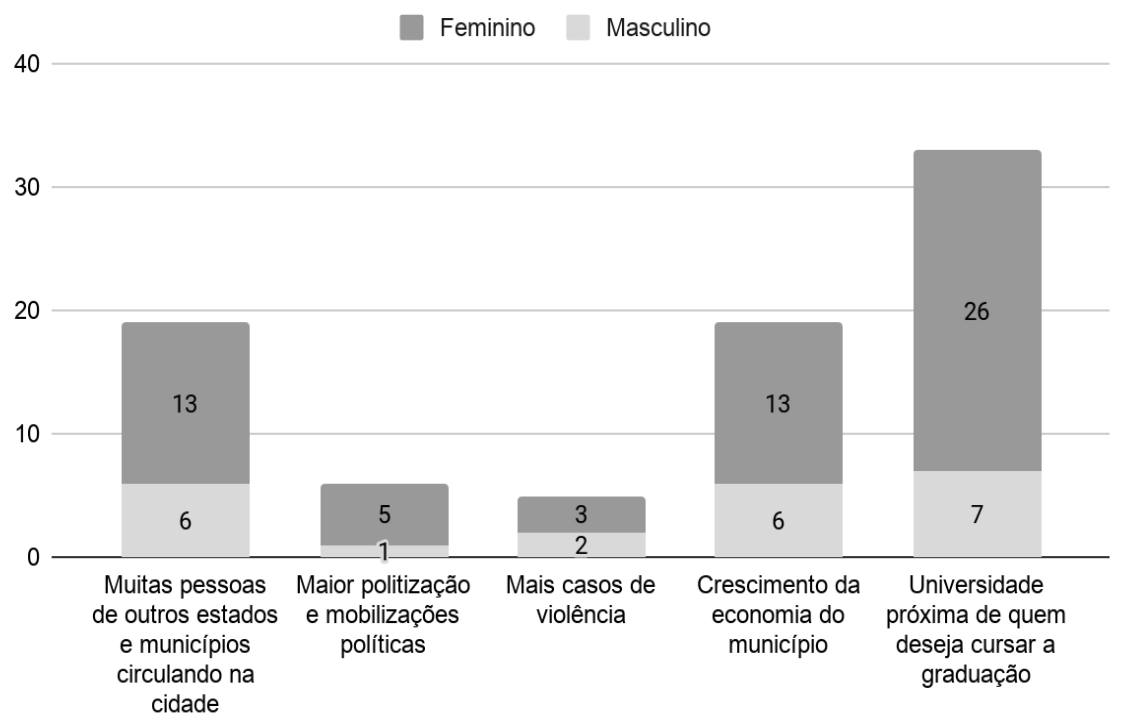

Fonte: Elaboração da autora com dados da pesquisa de campo, 2018.

Ao visualizar o gráfico 3, percebe-se que há uma ambiguidade nas respostas, como os entrevistados considerarem as mudanças no município com a instalação da Unipampa em Jaguarão como positivas, porém, quando perguntados sobre quais seriam essas mudanças positivas e negativas, boa parte dos indivíduos apontaram que não sabiam como a universidade estava funcionando, e um dos respondentes até questionou: "A universidade ainda está aberta?”, indagação esta que destacamos como primordial para pensarmos os dados e as discussões presentes neste artigo. Podemos atrelar estes diálogos da pesquisa de campo ao distanciamento da finalidade da IES, que está enfatizada no PDI - 2014-2018: “(...) a responsabilidade social é um compromisso que a Instituição deve ter para com a sociedade, expresso por meio de seus atos e atitudes que afetem positivamente a comunidade externa e a acadêmica, assumindo obrigações de caráter moral e social para a conquista do desenvolvimento". ${ }^{24}$

A opção de que há muitas pessoas de outros estados residindo na cidade pode ser tanto uma mudança de contexto negativa, quanto uma mudança positiva, pois raramente os alunos oriundos de outros estados conseguem empregos, enfrentam extensas burocracias para locar imóveis e, até mesmo, terem direito ao atendimento médico, e principalmente, assistência psicológica. 
Neste sentido, é importante trazer o resumo de uma matéria feita sobre os estudantes “de fora”. Em agosto de 2019, foi veiculada uma matéria no portal online do jornal Zero Hora ${ }^{25}$, o jornal que possui maior circulação no estado do Rio Grande do Sul, onde foram entrevistados alguns alunos da Universidade Federal de Pelotas (UFPEL), da Universidade Federal de Santa Maria (UFSM) e também da Unipampa, em que os mesmos relatam como é ser "de fora", chegar e permanecer dentro da universidade. Na matéria, há o depoimento de dois alunos que foram discentes do Campus Jaguarão e que relatam as situações com que se depararam ao chegar e viver na cidade:

Discente I: Primeiro, senti a mudança climática. Quando cheguei, fazia $16^{\circ} \mathrm{C}$. Eu achava muito frio. Em Salvador, o mínimo que faz é $2 \mathrm{I}^{\circ} \mathrm{C}$. Depois tem a questão cultural, de calor humano. As pessoas são distantes. Dentro da universidade eu me sinto acolhido, mas a cidade tem muito preconceito, primeiro por eu ser uma pessoa negra, depois por ser gay. Além disso, tem a questão das dificuldades financeiras, por estar longe de casa e não ter familiares, embora eu tivesse minha irmã aqui, mas ela também passava pelo mesmo. Os estudantes geralmente moram numa casa precária, que é o que dá para pagar.

Discente 2: $\mathrm{O}$ momento em que mais fiquei mal foi no primeiro ano. O quadro depressivo foi grande, porque eu não sabia o que fazer, estava num lugar completamente diferente, muito tempo em casa vendo cair chuva. Teve a questão de como eu ia chegar aqui, como ia me adaptar, como ia fazer tarefas que normalmente não era eu quem tinha de fazer. Uma das formas que utilizei para enfrentar isso, de me sentir isolada, foi adotar um cachorro, um vira-lata. Ajudou, só que aí aumentaram os gastos. Colabora a visão que a cidade tem dos estudantes. A cidade se fechou, e o aluno de fora tem dificuldade de se sentir integrado. Também não tem a parte do lazer. Quando a gente se junta dentro de uma casa para conversar, para ter um momento de lazer, os vizinhos se incomodam e a polícia aparece. E a faculdade tem muita pressão. Você tem de dar respostas rápidas, o que faz com que fique em modo de ataque todo o tempo, favorecendo a ansiedade. Quem não tem quadro depressivo tem algum problema com ansiedade.

Reisdorfer, ao pesquisar sobre as ressignificações identitárias de estudantes e suas relações com a comunidade da Universidade Federal da Integração Latino-Americana (UNILA), coloca como a universidade e a experiência acadêmica são compreendidas para além das dimensões reais de preparação acadêmica e profissional. Também caracteriza a relação entre a universidade e a comunidade como “(...) um processo construído por sujeitos de carne e osso. Muito mais que tijolos, livros, quadros e giz, uma universidade é um espaço de tensionamentos sociais, entrelaçamentos e trocas subjetivas". ${ }^{26}$

25 GAÚCHA ZH. Porto Alegre: Grupo Zero Hora, 20r8. Disponível em: «https://gauchazh.clicrbs.com.br/saude/noticia/2019/o8/depressao-e-ansiedade-de-universitarios-um-problema-emascensao-que-preocupa-especialistas-e-instituicoes-cjze96go8034toIpauol8bbez.html». Acesso em: 16 de dezembro de 2019 .

26 REISDORFER, Thiago Universidade e interculturalidade: ressignificações identitárias de estudantes da Universidade Federal da Integração Latino-Americana - UNILA (2008-2017). 2018. 303 f. Tese (Doutorado) - Centro de Ciências Humanas e da Educação, Universidade do Estado de Santa Catarina, Santa Catarina, 2018. p. 19. 


\section{REVISTA ANGELUS NOVUS}

Após este mapeamento de visões, vimos que, mesmo que a comunidade busque ver a universidade de maneira positiva, isso demonstra algo contraditório, pois grande parte deste grupo não vê a relevância da instituição em sua vida profissional e pessoal. Sendo assim, percebemos que este distanciamento da comunidade para com a universidade (e vice-versa), pode se dar a partir da sensação de não-pertencimento ${ }^{27}$, o que é um fator para se pensar novas estratégias de integração e de estabelecimento de redes que venham a fazer sentido no mundo da vida, que possam compreender e considerar quem vive no entorno e não está na instituição para valorizar suas vivências e saberes. ${ }^{28}$

\section{Considerações Finais}

$\mathrm{Na}$ sociedade dividida em classes, sabe-se que ainda a classe dominante possui um grande poder dentro da universidade, muitas vezes impedindo a sua real autonomia científica, que deve ser pautada no compromisso social que a mesma tem ${ }^{29}$. Tendo ainda sujeitos pertencentes às classes mais abastadas dominando o espaço público das instituições mais tradicionais, cabe pensar a qual classe uma universidade emergente como a Unipampa - que é composta por discentes de diversas culturas e pertencentes às classes populares - está servindo. Ainda não cabe definir a quem a Instituição de Ensino Superior (IES) busca servir, nossa pesquisa não conseguiu identificar essa questão, porém, futuramente há uma intenção de aprofundar o estudo sobre quem é a universidade e quem faz a universidade.

É relevante citar a concepção de universidade que está descrita no PDI - 2009-2013: "A concepção de universidade, aqui anunciada, exige uma prática pedagógica que dê materialidade aos princípios balizadores do Projeto Institucional. O conhecimento passa a ser compreendido como processo e não como produto".$^{30}$ Estes questionamentos possibilitam uma reflexão acerca do papel que a universidade está desempenhando no contexto local, se ela de fato inclui as camadas sociais emergentes dentro do contexto acadêmico ou não.

A maioria dos entrevistados não possui vínculo com a instituição, não concluiu a Educação Básica ou concluiu e não deu continuidade aos estudos, e tal realidade não é demérito, mas pode-se ponderar se estas pessoas reconhecem a universidade como um espaço que é seu por direito e que veio atender suas necessidades enquanto coletivo. Observam-se as análises dos gráficos, onde através dos cruzamentos de dados, percebe-se que há sim um conhecimento sobre a instituição, porém, uma minoria concorre a uma vaga no SISU, e que 
também o campus acaba por ter pouca relevância nos modos e objetivos de vida destas pessoas que até o momento vivenciam apenas o mundo do trabalho.

Ao que tange à visão da comunidade sobre a Unipampa - Campus Jaguarão, retomando o questionamento inicial, conclui-se que devemos pensar para quem a universidade está servindo, e analisando estes dados e ações da mesma, ela talvez contribua mais para outras regiões ou para sujeitos oriundos de outras localidades, do que para as pessoas que vivem nas regióes de fronteira, devendo como finalidade desenvolver um trabalho que possa atender a diversas áreas do município e da região, porém, os dados nos indicaram que ela ainda não alcançou especificamente nem mesmo a comunidade que a cerca.

\section{Anexo}

I. Instrumento de pesquisa

\section{unipampa \\ Universidade Federal do Pampa}

UNIVERSIDADE FEDERAL DO PAMPA

CAMPUS JAGUARÃO

\section{CURSO DE LICENCIATURA EM PEDAGOGIA}

\section{Programa de Educação Tutorial - PET Pedagogia}

Formulário nำ Data:

I - Qual seu sexo?

( ) Masculino ( ) Feminino

2 - Qual sua idade (em anos)?

3-Qual a sua zona/bairro de moradia?

4 - Qual a sua escolaridade?

( ) Ensino fundamental incompleto

( ) Ensino médio incompleto

( ) Cursando o ensino médio 
REVISTA ANGELUS NOVUS

( ) Ensino médio completo

( ) Ensino superior incompleto

( ) Cursando o ensino superior

( ) Ensino superior completo

( ) Pós graduação incompleta

( ) Cursando a pós graduação

( ) Pós graduação completa

5- Qual a área em que você é graduado (a)?

( ) Ciências Exatas e da Terra

( ) Ciências Biológicas

( ) Engenharias

( ) Ciências da Saúde

( ) Ciências Sociais Aplicadas

( ) Ciências Humanas

( ) Linguística, Letras e Artes

( ) Multidisciplinar

6 - Possuiu/possui algum vínculo com a Unipampa?

( ) Sim ( ) Não

7 - Se sim, realizou qual modalidade de curso?

( ) Graduação ( ) Pós-graduação ( ) Curso de formação

8 - Quando você teve conhecimento sobre a fundação da Unipampa?

( ) No ano de sua criação

( ) Após a formatura de algum amigo/parente dentro da instituição

( ) Após disputar uma vaga no Sistema de Seleção Unificada (Sisu)

( ) Após a implantação de seu prédio oficial no Bairro Kennedy

9 - Na sua opinião, a vinda da Unipampa para a cidade foi um acontecimento relevante?

( ) $\operatorname{Sim}$

( ) Não

Io - Levando em consideração a questão anterior, você acha que os cursos que o Campus Jaguarão oferece, são bons/relevantes?

( ) Sim

( ) Não

( ) Sim, mas a instituição poderia ter mais cursos

II - A universidade tem alguma relevância para você?

( ) Sim, na vida profissional

$80 \cdot$ ano XI, n. I6, $2020 \cdot$ ISSN 2179-5487 
( ) Sim, na vida pessoal

( ) Em ambas

( ) Não é importante

I2 - O que mudou na cidade após a vinda da Unipampa?

( ) Apenas mudanças negativas

( ) Apenas mudanças positivas

( ) Não sei

I3 - Quais foram as mudanças (positivas e negativas)?

( ) Muitas pessoas de outros estados e municípios circulando na cidade

( ) Maior politização e mobilizações políticas

( ) Mais casos de violência

( ) Crescimento da economia do município

( ) Universidade próxima de quem deseja cursar a graduação 